\title{
SINTESIS DAN KARAKTERISASI SIFAT OPTIK POLIMER FILM PVA-TCA-MB
}

\section{Jannatin ‘Ardhuha, Ni Nyoman Sri Putu Verawati, Muhammad Taufik, Syahrial Ayub}

\author{
Program Studi Pendidikan Fisika, \\ FKIP, Universitas Mataram \\ Jalan Majapahit No. 62, Mataram \\ E-mail: jardhuha@gmail.unram.ac.id
}

\begin{abstract}
Polyvinyl alcohol (PVA) based film polymers that contain trichloroacetic acid (TCA) and methylene blue $(M B)$ dye has been synthesized. The synthesis aimed to obtain material that can be applied as film dosimeter. Six PVA-TCA-MB thin film samples have been synthsized by varying $P V A$ grades and TCA composition. Characterization of optical property of the resulted polymer was undertaken by measuring samples absorption within wavelength range of $200 \mathrm{~nm}$ to $700 \mathrm{~nm}$. Absorption spectrum of samples showed an optimum between 547-644 $\mathrm{nm}$ that corresponds to purple colour and characteristic to MB absoption. Further analysis showed the influence of TCA concentration and storage periode of the polymer. Optimization of syntesis by evaluating synthesis condition, heating and storage time is yet to be done in order to obtain polymer that can be used as dosimeter with reproducible optical property.
\end{abstract}

Keywords: polimer film PVA-TCA-MB, absorption spectra, film dosimeter.

\section{PENDAHULUAN}

Dosimeter film merupakan salah satu topik dalam teknologi radiasi yang menarik banyak perhatian baik dari kalangan peneliti, praktisi kesehatan ataupun kalangan industri disebabkan karena cakupan penggunaannya yang luas dan kesesuaian karakteristiknya, (Akhtar S. dkk, 2016). Dosimeter film merupakan detektor yang ringan, mudah dibawa (portable) dan dapat diletakkan di berbagai lokasi, (Bhat N.V. et. al., 2007), (Akhtar S. et. al, 2013). Instrumen dalam bentuk film ini banyak dipergunakan karena kekasarannya, stabilitas masa penyimpanannya yang panjang, handal, mudah penanganannya, dapat diproduksi dalam skala yang besar, dan harganya relatif murah, (Akhtar S. et. al., 2013).

Prinsip kerja dari dosimeter film ini adalah adanya perubahan warna ketika film ini terpapar radiasi pengion, seperti paparan berkas sinar elektron dan sinar gamma (Ebraheem S. dkk, 2002), sinar x (M. J. Butson dkk, 2010), dan sinar ultaviolet (Abdel Fattah A. A. dkk, 2000). Dosimeter film dapat dikembangkan dari bahan dasar polimer dan indikator pewarna. Polimer dasar yang dapat dipergunakan antara lain polivinil alkohol (PVA), (Bhat, N.V., et. al., 2007), (Akhtar S. et. al, 2013, 2016); polikarbonat (Galante, AM dan Camposs, LL, 2012); polivinil klorida (PVC) (Kattan M dan Daher Y, 2016); dan polivinil butiral (PVB) (Abdel Fattah A. A. et. $a l, 2000)$.

Perpaduan antara pemilihan bahan dasar polimer dan indikator pewarna menghasilkan polimer film yang dapat berubah warna jika dipapari sinar radiasi. Modifikasi kedua bahan tersebut, tidak hanya merubah warna polimer, akan tetapi sifat kimia dan optik dari polimer film dapat berubah pula, disesuaikan dengan aplikasinya.

Penggunaan PVA sebagai bahan dasar pembuatan dosimeter ini banyak diminati, karena PVA mudah larut dalam air, tersedia dalam jumlah yang banyak, dan mudah untuk dicampurkan dengan berbagai indikator pewarna, (Bhat N.V. et. al., 2007). Serta suhu yang dibutuhkan dalam proses sintesis polimer 
film ini cukup rendah, (Bhat N.V. et. al., 2007).

Indikator pewarna yang dapat dicampurkan ke dalam PVA antara lain methylene biru (MB) dan methyl merah (MR) (Akhtar S., et. al., 2013); bromophenol merah (BPR), brilliant yellow (BY) (El-Kelany M. dan Ebraheem S., 2011); ethyl violet dan bromophenol biru (BPB) (Ebraheem S. dan ElKelany M., 2013); cresol merah (CR) (S. Ebraheem et. al., 2002); tetrazolium violet (Emi R. G. dkk, 2007); dan methyl viologen (Lavallea M. et. al., 2007).

Selain penggunaan polimer dasar dan indikator pewarna, penambahan tricloroacetate (TCA) dan chloral hydrate dapat pula dilakukan untuk memberikan sifat fleksible plastik dari dosimeter film. Penelitian M. ElKelany dan S. Ebraheem (2011) menunjukkan bahwa kombinasi polivinil alkohol (PVA) bromophenol biru (BPB) - brilliant yellow (BY) - dan tricloro-acetat (TCA ) dapat dipergunakan sebagai dosimeter film pada dosis radiasi yang rendah (di bawah 6Gy). Kombinasi polimer film lainnya adalah PVATCA-CR dapat pula dipergunakan sebagai alternatif dosimeter dengan dosis radiasi 57,5Gy, (Saion E.A. et. al., 2004).

Kestabilan fungsi dosimeter film ini terhadap waktu penyimpanan polimer merupakan salah satu faktor yang sangat penting, ketika polimer film ini akan perdagangkan. Berdasarkan penelitian yang dilakukan oleh Akhtar S. et. al. (2013) menunjukkan bahwa terjadi sedikit penurunan nilai serapan optik polimer film PVA dengan pewarna methylene blue setelah polimer tersebut disimpan di tempat yang terang selama 30 hari. Selain itu, hasil penelitian ElKelany M. dan Ebraheem S. (2011) menunjukkan bahwa nilai serapan optik dari polimer film PVA-BPB-BY-TCA yang disimpan selama 60 hari memiliki kestabilan yang baik.

Penelitian Verawati (2012) melaporkan bahwa polimer film PVA-TCA-MB mengalami perubahan warna dari biru keunguan sampai menjadi kuning akibat diradiasi radiasi sinar gamma. Dalam artikel ini akan dipaparkan mengenai karakteristik sifat optik polimer film PVA-TCA-MB sebelum diradiasi dengan sinar gamma.

\section{METODE PENELITIAN}

Bahan yang dipergunakan dalam mensintesis polimer PVA-TCA-MB adalah polyvinyl alcohol (PVA) teknis Kurray Asia, PVA Bioworld (Mw 18000), PVA Merck (Mw $72000 \mathrm{~g} / \mathrm{mol}$ ), methylene blue (MB), trichloroacetic acid (TCA), etanol, $\mathrm{NaOH}$ (10\%), air aquades. Metode yang dipergunakan dalam mensintesis polimer film ini merujuk pada metode Verawati (Verawati, 2012). Variasi massa TCA yaitu sebanyak $1 \mathrm{gr}$, 2gr dan 3gr ditambahkan dalam sintesis polimer yang menggunakan dua jenis PVA (PVA teknis dan PVA pro analisis Bioworld). Desain pelabelan sampel ditunjukkan pada Tabel 1.

Tabel 1. Desain Polimer Film PVA-TCA-MB

\begin{tabular}{|c|c|c|c|}
\hline \multirow{2}{*}{ Jenis PVA } & \multicolumn{3}{|c|}{ Komposisi TCA } \\
\cline { 2 - 4 } & 1gr & 2gr & 3gr \\
\hline PVA teknis & Sampel 1 & Sampel 2 & Sampel 3 \\
\hline PVA pro analisis (p.a) & Sampel 4 & Sampel 5 & Sampel 6 \\
\hline
\end{tabular}

Catatan: Komposisi MB untuk semua sampel sama

Spektrum serapan optik dari polimer ini diukur dengan spektrofotometer UV-200-RS

(L.W. Scientific) dan spektrofotometer UV1601 PC (Shimadzu). Polimer yang diuji harus 
dalam keadaaan kering. Pengujian dilakukan untuk 3 variasi waktu penyimpanan polimer, yaitu hari ke-17, 24 dan 30.

\section{HASIL DAN PEMBAHASAN}

Telah berhasil disintesis enam buah polimer film PVA-TCA-MB dengan variasi jenis PVA (teknis dan pro analisis) dan massa TCA. Terdapat perbedaan waktu sampel mengering secara sempurna antara sampel yang terbuat dari PVA teknis dan PVA pro analisis (p.a). Sampel 1, 2 dan 3 dapat kering secara sempurna pada hari ke-10. Sedangkan sampel 4, 5 dan 6, waktu keringnya lebih lama yaitu 14 hari. Selain waktu pengeringan, ketebalan dari keenam sampel juga berbeda, yaitu berkisar antara $0,17-0,28 \mathrm{~mm}$, seperti yang ditunjukkan pada Tabel 2. Sampel 3 memiliki ketebalan yang paling besar yaitu $0,28 \mathrm{~mm}$. Pengujian serapan optik dari keenam sampel dilakukan sebanyak tiga kali, yaitu pada hari ke-17, ke-24 dan ke-30, pada daerah panjang gelombang $300-700 \mathrm{~nm}$. Tabel 3 menunjukkan puncak panjang gelombang serapan maksimum dan nilai serapan optiknya untuk 3 waktu penyimpanan sampel.

Tabel 2. Ketebalan Polimer FIm PVA-TCA-MB

\begin{tabular}{|c|c|c|c|c|c|c|}
\hline Sampel & 1 & 2 & 3 & 4 & 5 & 6 \\
\hline$(\mathbf{m m})$ & 0,21 & 0,24 & 0,28 & 0,19 & 0,17 & 0,21 \\
\hline
\end{tabular}

Tabel 3. Spektrum Serapan Optik Polimer Film PVA-TCA-MB

\begin{tabular}{|c|c|c|c|c|c|c|}
\hline \multirow{2}{*}{ Sampel } & \multicolumn{5}{|c|}{ Waktu Penyimpanan Sampel } \\
\cline { 2 - 7 } & \multicolumn{2}{|c|}{$\mathbf{1 7}$ hari } & \multicolumn{2}{c|}{$\mathbf{2 4}$ hari } & \multicolumn{2}{c|}{ 30 hari } \\
\cline { 2 - 7 } & $\lambda_{\text {mak }}(\mathbf{n m})$ & $\begin{array}{c}\text { Serapan } \\
\text { optik (A) }\end{array}$ & $\lambda_{\text {mak }}(\mathbf{n m})$ & $\begin{array}{c}\text { Serapan } \\
\text { optik (A) }\end{array}$ & $\lambda_{\text {mak }}(\mathbf{n m})$ & $\begin{array}{c}\text { Serapan } \\
\text { optik (A) }\end{array}$ \\
\hline 1 & 640 & 0,90 & 628 & 0,37 & 605 & 1,84 \\
\hline 2 & 640 & 0,75 & 627 & 0,61 & 604 & 2,21 \\
\hline 3 & 620 & 0,72 & 655,5 & 0,52 & 608 & 3,01 \\
\hline 4 & 608,5 & 1,69 & 605,5 & 2,30 & 604,5 & 2,15 \\
\hline 5 & 607,5 & 2,79 & & & 606 & 2,68 \\
\hline 6 & 631,5 & 1,13 & 609 & 2,91 & 547,5 & 0,15 \\
\hline
\end{tabular}

Hasil uji serapan polimer, pada hari ke17 menunjukkan untuk sampel 1-3, panjang gelombang serapan maksimum berkisar antara $620-640 \mathrm{~nm}$, dimana nilai serapan untuk sampel 1 sebesar 0,90A, sampel 2 dan 3 sebesar 0,75A dan 0,72A. Untuk sampel $4-5$, panjang gelombangnya hampir sama yaitu $608,5 \mathrm{~nm}$ dan 607,5 nm. Sedangkan nilai serapan optiknya selisih 1,1 . Untuk sampel 4 sebesar 1,69A dan sampel 5 sebesar 2,79A. Sedangkan untuk sampel 6 panjang gelombang maksimumnya terletak pada $631,5 \mathrm{~nm}$ dan nilai serapan optiknya $1,13 \mathrm{~A}$.
Pada hari ke-24, untuk sampel 1 dan 2, panjang gelombang maksimum bergeser ke arah kiri, yaitu pada 628 dan $627 \mathrm{~nm}$. Sedangkan pada sampel ke-3, panjang gelombang maksimumnya naik menjadi $655,5 \mathrm{~nm}$. Dibandingkan hari ke-17, nilai serapan dari sampel 1-3, mengalami penurunan. Penurunan panjang gelombang serapan maksimum juga terjadi pada sampel 4 dan 6. Akan tetapi, nilai serapan optik untuk kedua sampel ini mengalami peningkatan. Pada sampel 5, tidak diperoleh data, karena pada saat pengukuran sampelnya rusak. 
Spektrum serapan optik pada pengukuran hari ke-30 untuk sampel $1-5$ menunjukkan pola yang sama, dimana panjang gelombang maksimumnya terletak di sekitar $604-608 \mathrm{~nm}$. Serapan optik polimer tertinggi sebesar 3,01 didapat pada sampel 3. Terdapat perbedaan yang cukup mencolok pada sampel 6, dimana panjang gelombang serapan maksimumnya terletak pada 547,5nm dan nilai serapan optiknnya sangat kecil yaitu sebesar 0,15 .

Jika dibandingkan nilai serapan optik terhadap waktu penyimpanan polimer, untuk sampel 1 - 4, diperoleh kecenderungan data untuk hari ke-17 dan ke-30 yaitu semakin lama waktu penyimpanan sampelnya maka semakin tinggi nilai serapan optik polimernya. Untuk sampel 5, nilai serapannya relatif sama untuk hari ke-17 dan ke-30. Sedangkan untuk sampel 6, kecenderungan nilai serapannya berkebalikan dengan sampel 1-3, dimana semakin lama waktu penyimpaan sampel, maka nilai serapannyan makin menurun. Seperti yang ditunjukkan pada Gambar 1 berikut.

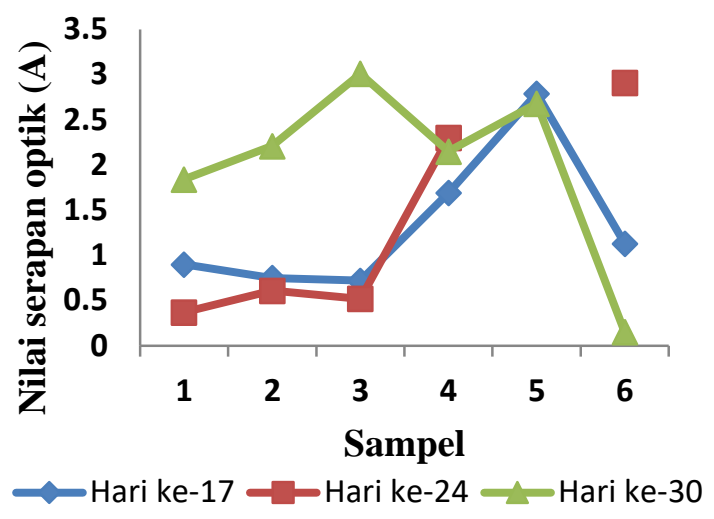

Gambar 1. Grafik hubungan antara nilai serapan dan waktu penyimpanan polimer film PVA-TCA-MB untuk tiap sampel.

Analisis lebih lanjut dapat dilakukan untuk mengetahui besarnya koefisien serapan optik $(\mu)$ dari keenam sampel, seperti yang ditunjukkan pada Tabel 4. Besarnya koefisien serapan optik berdasarkan data hari ke-30, diperoleh untuk sampel 1-6 adalah 20,18 $\mathrm{mm}^{-}$ 1, 21,21 mm $\mathrm{mm}^{-1}, 24,26 \mathrm{~mm}^{-1}, 26,06 \mathrm{~mm}^{-1}, 36,31$ $\mathrm{mm}^{-1}$ dan $1,64 \mathrm{~mm}^{-1}$. Sampel 5 dan 6 adalah sampel yang memiliki koefisien terbesar dan terkecil.

Tabel 4. Koefisien Serapan Optik Polimer Film PVA-TCA-MB

\begin{tabular}{|c|c|c|c|c|c|c|}
\hline Sampel & $\mathbf{1}$ & $\mathbf{2}$ & $\mathbf{3}$ & $\mathbf{4}$ & $\mathbf{5}$ & $\mathbf{6}$ \\
\hline $\boldsymbol{\mu}(\mathbf{1} / \mathbf{m m})$ & 20,18 & 21,21 & 24,26 & 26,06 & 36,31 & 1,64 \\
\hline
\end{tabular}

Berdasarkan analisis hasil spektrum serapan dari kedua jenis PVA yang digunakan untuk mensintesis polimer lapisan tipis PVATCA-MB menunjukkan bahwa pita absorpsi sampel terletak pada daerah cahaya tampak, yaitu berkisar pada panjang gelombang 547644nm. Absorbansi dari dosimeter yang tidak diradiasi sinar gamma pada pita absorpsi 575nm menunjukkan karakteristik warna ungu (Saion E. A., et. al., 2004) dan 668nm untuk warna biru tua (Akhtar, S. et. al., 2016). Range ini bersesuaian dengan warna sampel yaitu biru tua atau mendekati warna ungu.
Nilai serapan optik dari keenam polimer film PVA-TCA-MB ini terlihat masih berfluktuatif, seperti yang ditunjukkan pada Tabel 3. Sensitivitas nilai serapan dari suatu dosimeter yang belum diradiasi (unirradiated) tergantung dari konsentrasi dan temperatur dari larutan pembentuk polimer selama proses pembuatan (sintesis) lapisan tipis (Akhtar, S, et. al, 2016). Konsentrasi yang dimaksud adalah konsentrasi dari polyvinil alkohol (PVA), methylene blue (MB), trichloroacetic acid (TCA).

Hal ini didasarkan pada hasil penelitian yang dilakukan oleh Saion (2004), Susilawati 
dan Aris (2009) menyatakan bahwa intensitas serapan bergantung pada konsentrasi dari TCA pada polimer PVA-TCA-CR (cresol red). Semakin rendah konsentrasi TCA maka makin berkurang pula intensitas (nilai) serapan dari polimer tersebut. Sedangkan berdasarkan penelitian Akhtar S. (2013), nilai serapan akan meningkat seiring dengan peningkatan konsentrasi pewarna polimer (MB). Atau dengan kata lain semakin besar konsentrasi TCA dan MB, maka nilai serapan optik dari polimer akan semakin meningkat.

Tempat penyimpanan sampel juga memberi pengaruh terhadap kestabilan pengukuran sampel. Berdasarkan penelitian yang dilakukan oleh Akhtar S. et. al. (2013) menunjukkan bahwa terdapat pengaruh tempat penyimpanan sampel (tempat gelap dan terang) terhadap nilai absorbansi sampel ketika pengukuran dilakukan pada waktu yang berbeda.

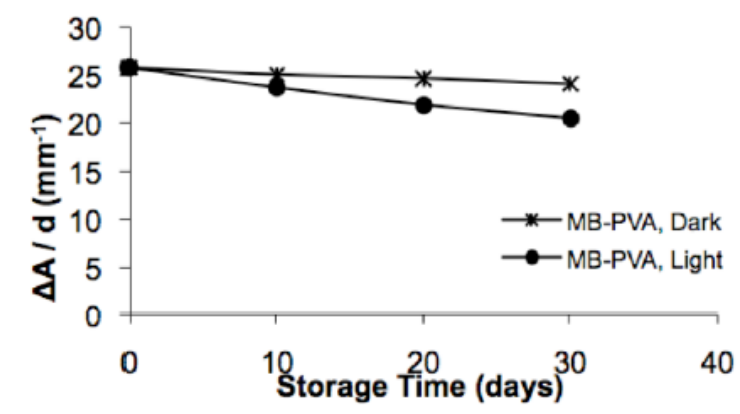

Gambar 2. Nilai koefisien serapan optik dari polimer MB-PVA yang tidak diradiasi yang disimpan selama 30 hari, (Akhtar S. dkk, 2013).

Dimana polimer MB-PVA yang disimpan di tempat yang terang selama 30 hari, nilai absorbansinya mengalami sedikit penurunan, seperti yang ditunjukkan pada Gambar 2. Di sini terlihat bahwa terdapat perubahan nilai serapan optik sampel terhadap waktu penyimpanan sampel. Dimana semakin lama waktu penyimpanannya, maka koefisien serapannya makin berkurang.

Kombinasi dari jenis PVA, massa TCA tempat dan waktu penyimpanan sampel dapat mempengaruhi karakteristik optik dari polimer film PVA-TCA-MB yang telah disintesis. Ketidakteraturan pola nilai serapan optik dari keenam sampel ini dapat disebabkan oleh beberapa faktor. Faktor pertama adalah proses pembuatan larutan polimer dan konsentrasi dari methylene blue (MB) yang dipergunakan. Prosedur sintesis polimer PVA-TCA-MB ini didasarkan atas penelitian yang dilakukan oleh Verawati (2012). Pada penelitian tersebut, dikatakan bahwa polimer lapisan tipis dapat kering (dapat memadat dan dapat diangkat dari cetakan) pada hari ke-5. Akan tetapi, dalam pelaksaannya waktu pengeringan dari keenam sampel lebih dari 5 hari. Sampel 1-3 kering pada hari ke-10 dan sampel 4-6 waktu keringnya pada hari ke-14.
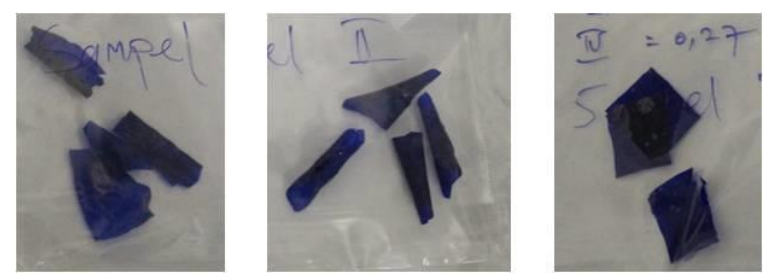

Gambar 3. Keadaan fisik sampel 1, 2 dan 3 pada hari ke-17. Urutan dari kiri ke kanan adalah sampel 1, sampel 2 dan sampel 3.

Selain itu kondisi sampel yang diperoleh juga berbeda, dimana sampel yang terbuat dari PVA teknis (sampel 1-3) mudah diangkat dan terlihat seperti lapisan plastik. Namun, terdapat bercak pecah-pecah pada polimer film-nya. Pada pengukuran hari ke-17, keadaan fisik sampel 1 mudah mengkerut, terdapat warna putih-putih dan mudah pecah. Sampel kedua keadaannya hampir sama dengan sampel pertama, hanya saja mudah menggulung. Sedangkan pada sampel ketiga, teksturnya lebih rata dan halus. Seperti yang ditunjukkan pada Gambar 3.Sedangkan untuk sampel yang terbuat dari PVA p.a (sampel 4 5) tekstur polimernya lebih halus, akan tetapi mudah hancur. Hal ini mengisyaratkan perlunya optimasi pada langkah-langkah percobaan. Sehingga waktu kering dari 
polimer dapat lebih cepat dan keadaan fisik sampel layak dipergunakan sebagai dosimeter.
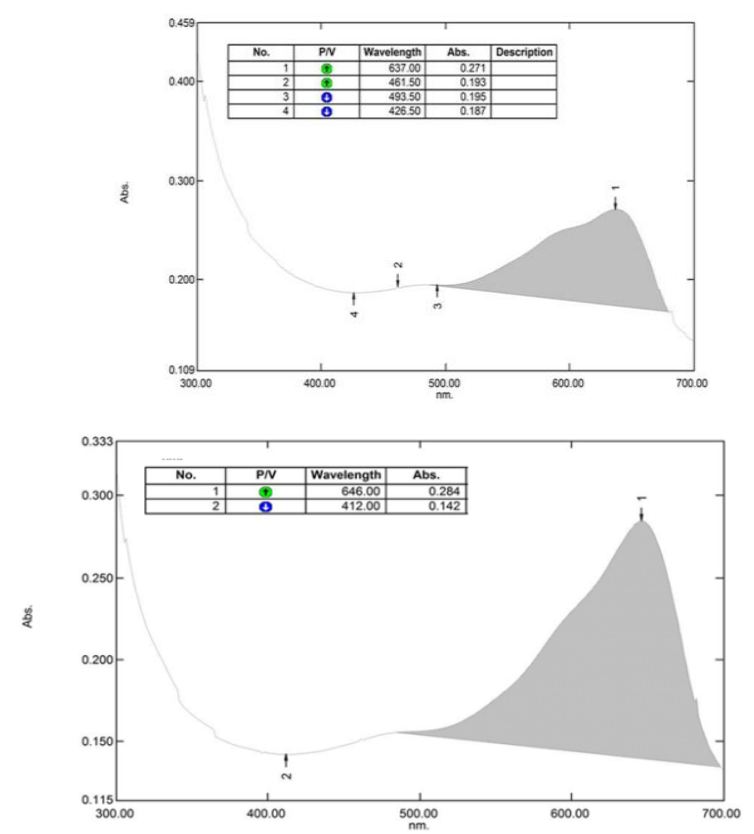

Gambar 4. Spektrum absorpsi dari polimer lapisan tipis PVA(teknis)-TCA-MB (kiri) dan PVA(p.a)-

TCA-MB (kanan) yang diukur pada hari ke-7.

Faktor kedua yang dapat mempengaruhi karakterisitik polimer adalah konsentrasi dari MB yang dipergunakan. Dalam penelitian ini larutan pewarna dibuat dari 0,08 gram MB dilarutkan dalam $50 \mathrm{ml}$ etanol dan ditambah larutan $\mathrm{NaOH}$ 10\%. Hal ini menyebabkan kandungan air dalam larutan polimer ini tinggi. Sehingga dibutuhkan waktu yang lebih lama bagi sampel untuk menguapkan air tersebut pada temperatur ruang. Hal ini juga berimbas pada konsentrasi MB dalam polimer rendah. Ini mungkin merupakan salah satu penyebab mengapa polimer yang disintesis lama kering dan mudah rusak. Salah satu pendekatan yang ditawarkan adalah dengan mengurangi volume larutan perwarna yang dipergunakan dalam sintesis polimer PVATCA-MB. Hal ini mengacu pada prosedur sintesis yang dilakukan oleh Saion et. al. (2009), Susilawati dan Aris (2012), Ebraheem S. dan El-Kelany M. (2013), bahwa penggunaan pewarna dalam polimer dosimeter hanya digunakan sebanyak $1 \mathrm{ml}$ dari cadangan larutan pewarna (stock of dye solution) atau 1mg. Pendekatan ini telah dicoba untuk dilakukan, dimana waktu sampel kering menjadi lebih cepat yaitu 6 hari dan diperoleh polimer yang jauh lebih tipis, jika dibandingkan dengan ketebalan dari 6 sampel sebelumnya. Serta polimer filmnya berwarna biru muda transparan. Spektrum serapan yang diperoleh dengan menggunakan pendekatan ini lebih stabil jika dibandingkan dengan sampel sebelumnya. Sampel PVA(teknis)-TCA (1gram)-MB diperoleh nilai serapan sebesar 0,284 pada panjang gelombang maksimum 646 nm. Sedangkan pada sampel PVA(p.a Merck) -TCA(1 gram)-MB, nilai serapan 0,271 pada $637 \mathrm{~nm}$. Pengukuran serapan ini dilakukan pada hari ke-7. Spektrum serapan dari sampel 7 dan 8 ditunjukkan pada Gambar 4. Nilai serapan polimer ini rendah dikarenakan oleh kandungan pewarna mengalami penurunan jumlah. Perlakuan lain yang dapat dilakukan adalah dengan memanaskan larutan PVA dan air aquades pada temperatur $80^{\circ} \mathrm{C}$ waktunya lebih lama, yaitu sekitar 2 jam. Seperti yang dituliskan dalam prosedur penelitian Saion dan Susilawati. Perlakuan ini dapat meningkatkan homogenitas dan konsentrasi larutan PVA.

\section{KESIMPULAN}

Telah berhasil disintesis polimer lapisan tipis PVA-TCA-MB dengan dua tipe PVA yang dipergunakan yaitu PVA teknis dan PVA pro analisis. Berdasarkan spektrum absorpsi dari 6 sampel yang dipergunakan dalam penelitian ini, pita absorpsi sampel terletak pada daerah cahaya tampak, yaitu berkisar pada panjang gelombang 547-644nm. Range ini bersesuaian dengan warna sampel yaitu biru tua atau mendekati warna ungu.

Pengukuran kestabilan dari sampel ditinjau dari waktu penyimpana sampel sebelum diradiasi menunjukkan nilai serapan masih berfluktaktif. Sampel yang telah 
disintesis ini belum dapat dipergunakan sebagai dosimeter, karena sifat fisiknya yang mudah pecah, menggulung dan hancur, serta lama untuk mengering.

Diperlukan optimasi perlakuan dalam proses pembuatan polimer lapisan tipis PVATCA-MB, baik dari temperatur pemanasan, lama pemanasan, konsentrasi larutan pewarna ataupun konsentrasi dari PVA yang dipergunakan. Dengan melakukan optimasi ini diharapkan diperoleh polimer yang dapat berfungsi sebagai dosimeter yang memiliki kestabilan yang tinggi, baik sebelum dan sesudah proses radiasi dalam variasi waktu pemyimpanan dosimeter.

\section{UCAPAN TERIMA KASIH}

Penulis mengucapkan terima kasih pada Lembaga Penelitian dan Pengabdian pada Masyarakat (LPPM) Universitas Mataram atas dukungan dana hibah PNBP tahun 2017 terhadap penelitian ini.

\section{REFERENSI}

Abdel-Fattah, A. A., El-sayed A. Hegazy, H. Ezz El-Din. 2000. Thymol-blue dyed poly(vinyl butyral) films for monitoring ultraviolet radiation, Journal of Photochemistry and Photobiology A: Chemistry 137, 3743.

Akhtar, S., Hussain, T., Shahzad, A., \& Qamar-ul-Islam. 2013. The Feasibility of Reactive Dye in PVA Films as High Dosimeter. Basic \& Applied Sciences, 420-423.

Akhtar, S., Shahzad, A., Bashir, S., Hussain, M. Y., Akhtar, N., \& Kang, Z. 2016. Improved Performance of Radiochromic Films for High Dose Dosimetry. Radioprotection , 129-133.

Bhat, N. V., Nate, M. M., Bhat, R. M., \& Bhatt, B. C. 2007. Effect of $\gamma-$ irradiation on polyvinyl alcohol films doped with some dyes and their use in dosimetric studies. Indian Journal of Pure \& Applied Physics , 45, 545-548.

Butson, M. J., Yu, P. K. N., Cheung, T., \& Alnawaf, H. 2010. Energy Response of the New EBT2 Radiochromic Film to X-Ray Radiation. Radiation Measurements, 45(7), 836-839.

Ebraheem, S. \& El-Kelany, M. 2013. Dosimeter Film Based on Ethyl VioletBromophenol Blue Dyed Poly(Vinyl Alcohol), Journal of Polymer Chemistry, 3, 1-5.

Ebraheem, S., Eid, S. \& Kovacs, A. 2002. A New Dyed Poly (Vinyl Alcohol) Film for High-Dose Applications. Radiation Physics and Chemistry, 63(3-6), 807811.

Emi R. G., Andras K. \& Fletcher J. J. 2007. Dosimetry characterization of tetrazoliumviolet polyvinylalcohol films. Radiat. Phys. Chem., 76, 15191522.

Galante A. M. \& Campos L. L. 2012. Mapping radiation fields in containers for industrial $\gamma$-irradiation using polycarbonate dosimeters. Appl Radiat Isot, 70(7), 1264-6.

Kattan, M. \& Daher, Y. 2016. The use of polyvinyl chloride films dyed with methyl red in radiation dosimetry. International Journal Radiation Research, 14(3), 263-267.

Lavallea, M., Cordaa, U., Fuochia, P.G., Caminatia, S., Venturib, M., Kova' csc, A., Baranyaic, M., Sa' fra'nyc, A., \& Miller, A. 2007. Radiochromic film containing methyl viologen for radiation dosimetry, Radiation Physics and Chemistry, 76, 1502-1506.

M. El-Kelany , S \& Ebraheem. 2011. Response and Stability of Radiation Monitoring Labels to Gamma Rays. Journal of Radiation Research and Applied Sciences, 4(3B), 869-877.

Saion, E., Susilawati, Doyan, A., Daud, W., Zaki, M., \& Rahman, A. 2004. The 
Effects of Radiation on Optical Properties Of Dyed Poly (Vinyl Alcohol) Blends. Solid State Science and Technology, 12(1), 192-198.

Susilawati \& Doyan A. 2009. Dose Response and Optical Properties of Dyed Poly Vinyl Alcohol-Trichloroacetic Acid. American Journal of Applied Sciences, 6(12), 2071-2077.

Verawati, N. N. S. P. 2012. Serapan Optik Polimer PVA-TCA-MB yang Diradiasi Sinar Gamma. Pijar MIPA, 7(2), 6064. 